\title{
Teachers of Psychiatry Meeting in Chengdu
}

Li Yuanyuan Phd

Department of Psychiatry, West China Hospital of Sichuan University, Chengdu, Sichuan Province, China

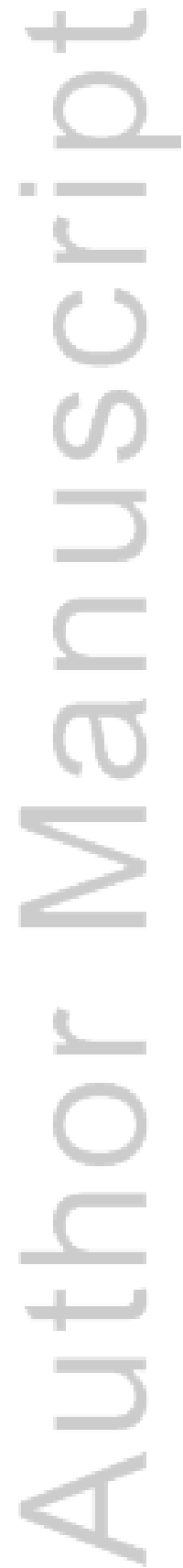

This is the author manuscript accepted for publication and has undergone full peer review but has not been through the copyediting, typesetting, pagination and proofreading process, which may lead to differences between this version and the Version of Record. Please cite this article as doi: 10.1111/appy.12306

This article is protected by copyright. All rights reserved. 


\section{Teachers of Psychiatry Meeting in Chengdu}

There is a big lack of psychiatrists in China. With the goal of improving the quality of education, service and research, the Teachers of Psychiatry (TOP) Meeting in the Asia-Pacific region was held in Chengdu from 7th to 8th May, 2016. The TOP meeting was organised with the participation of Pacific-Rim College of Psychiatrists (PRCP) and the Mental Health Center of West China Hospital. The meeting brought together many experts in psychiatric education around the Asia-Pacific region. Sixteen internationally-renowned experts in the field of psychiatry were invited to be course trainers and 150 Chinese senior psychiatrists were invited to partake in who work in the field of mental health in China - either in academia or in public health care.

The training course included two plenary sessions: Leadership and Quality Assurance in Psychiatry; and the Effective Research Skills. There were also six concurrent workshops focused on evaluation methods for educational programs, clinical service and research. This report will give a summary account of this meeting. 


\section{Leadership and Quality Assurance in Psychiatry}

After the welcome address, the Leadership and Quality Assurance in Psychiatry forum commenced on the morning of 7thMay, Prof. Norman Sartorius, former Director of the Mental Health Program of the World Health Organization (WHO) and former President of the World Psychiatric Association (WPA), gave a lecture on Training Psychiatrists for Future Leadership. The lecture discussed three important issues: 1) characteristics of a good psychiatrist; 2) the requirements and components of producing good leaders in psychiatry; 3 ) how to develop the leadership qualities.

The second lecture was given by Prof. Yu Xin, Director of Peking University Institute of Mental Health and President of the Chinese Psychiatric Association(CPA). His topic was Self Health Care of Psychiatrists. He presented and analyzed the challenges and pressure the psychiatrists face and suffer. He gave a lot of advice on the self-care of psychiatrists- including how to deal with the bad mood, how to to cultivate humanistic literacy, and so forth.

In the third lecture, Prof. Mian-Yoon Chong, former President of Taiwan 
Changgeng Hospital and former Chair of the Psychiatry Department in Changgeng Hospital, talked about the Management Skills in Hospital Administration, such as defining the purpose and objectives, knowing and managing risk, and the Root Cause Analysis. He also shared his experience when he worked in his former Hospital.

Prof. Kua Ee Heok gave the fourth lecture focusing on Leading the Department: an excellent leader should have intra-psychic(including confidence, wide interest, vision and diplomatic skills) and extra-psychic (including mentorship, the ability to delegate responsibilities, good listening and rewarding know-how);rethinking the curriculum during clinical practice and having good habits are also important qualities for a good department leader.

The last lecture in that morning was given by Prof. Helen Herrman, Director of the World Health Organization (WHO) Collaborating Centre for Mental Health in Melbourne, President-Elect of the World Psychiatric Association (WPA), President of the Pacific Rim College of Psychiatrists (PRCP), and President of the International Association of Women's 
Mental Health. She talked about Building International Links in Psychiatry. The main points of this lecture were: 1) the importance of building international links to the development of psychiatry in all countries; 2) the introductions of the international professional associations which can help build the links, such as World Psychiatric Association (WPA), World Health Organization (WHO), Pacific Rim College of Psychiatrists(PRCP); 3)some recommendations that building international links is a collaboration among the patients, the carers and the clinicians that education, research and quality improvement in mental health care are in the very need of.

\section{Effective Research Skills}

The Effective Research Skills in Psychiatry forum commenced onthe morning of 8thMay. Prof. Norman Sartorius talked about how to select a research subject. The reasons we do research at this point of timeencompass career development, building thesocial network of nice people and powerful teams, answering a question of interest, helping learn the use of a technique, and so forth. He suggested that the study should not take much personal time and little would have to be 
sacrificed to do it ;you should have enough time to complete the study before you change your position. Prof. Norman Sartorius said that a good clinical study should have goodfeasibility, detailed as follow: 1) it uses simple methods which can be learned quickly and be done without the help of others; 2) the work of the study can be incorporated into everyday tasks; 3 ) there also must be a clear statement of roles and rights in the study ; 4) it will be great if there is a faint chance that some funding will become available for the study;5) there is an agreement which makes it possible to have access to data for further publications. Finally, Prof. Sartorius shared some examples of studies which are of high $\mathrm{SCl}$ contributory factor loadings

Prof. Li Tao, the director of the Mental Heath Center of West China Hospital, gave a lecture of Opportunities and Challenges of Mental Health. She introduced the National Institute of Mental Health (NIMH), and presented the developmental trends of studies in NIMH from 2008 to 2015. The key research priorities included: (1) defining the mechanisms of complex behaviors; (2) charting mental illness trajectories to determine when, where, and how to intervene; (3) striving for prevention and cures; (4) strengthening the public health 
impact of NIMH-supported research.

\section{Workshops for Junior and Senior Psychiatrists}

On the afternoon of 7th May there were six workshops divided into two series for the Junior and senior psychiatrists. Every workshop approximately lasted 1.5 hours.

The junior workshops were for the young psychiatrists who haveworked less than 5 years, focusing on the basic clinical skills and research skills. There were three topics covered: (1) How to interview/assess a patient; (2) How to write up a research paper; and (3) How to present a paper.

Prof. PhilipMorris, Board Director of the Pacific Rim College of Psychiatrists (PRCP) and President ofthe Australian and New Zealand Mental Health Association (ANZMHA), and Prof. Hao Wei, Director of Mental Center in Xiangya Hospital co-chaired the first topic. They usedrole-playing techniqueto illustrate how to interview a patient and the heavy side effects of antipsychotic medicationswould be like tothe young psychiatrists. Then Prof. PhilipMorris explained the side effects 
from pharmacokineticsto pharmacogenetics perspective, and showed the way to monitor side effects.

Prof. Norman Sartorius, Prof. Xiang Yutao and Prof. Guo Wanjun who works in the West China Hospital, co-chaired the other two topics. They taught the young psychiatrists how to search a valuable article online, how to read the article and how to make their research step by step. They shared their experience in doing excellent researches and writing good articles even though there was lack of high-technology, money and English skills. They encouraged young psychiatrists to practice more.

- The senior workshops were for the psychiatrists who have worked more than 5 years, focusing on the administration.There were also three topics covered. Prof. Mian-Yoon Chong and Prof. Kuang Weihong, who is the Deputy Director of the Mental Health Center of West China Hospital, co-chaired the first workshop on How to Evaluate a Clinical Service. They pointed out that as the project time managementwas crucial, psychiatristsshould evaluate the priorities and the urgency of clinical affairs before makingthe schedule. To improvemedical servicequality, psychiatrists should abide by the patient-centered methodology. There 
were four steps to optimize the medical service quality: plan, do, check and act(PDCA). Prof. Mian-Yoon Chong demonstrated how to use PDCA to make electro-shock therapy better.

Prof. Helen Herrman and Prof. Huang Yi, who is the Education Chief of the Mental Health Center of West China Hospital, co-chaired the second workshop on How to Evaluate an Education Program. In the second workshop, Prof. Helen Herrman discussed various topics such as the objective, target and implementation of the education evaluation and shared some examples from Royal Australian and New Zealand College of Psychiatrists (RANZCP) with us. She pointed out that the objective of the education evaluation is primarily for improving teaching quality, and the evaluation should be sustainable, practical and taking into account the interests and suggestions from a multitude of parties at stake; likewise, the content of the evaluation covers the teaching environment, faculty resources, course content and students' knowledge, skills, attitudes and behaviors as well as students' performance in their work in long-term. 
The last workshop for senior group was co-chaired by Prof. Helen Herrman and Prof. Deng Hong, who also works in the Mental Health Center of West China Hospital. The topic was working with Service Users and Care-givers. They talked about the concept of shared decision-making(SDM); SDM falls into the definition that the doctors and patients jointly make medical/treatment decisions by discussion through their collective endeavor. The advantages of SDM have been embodied that it does foster the patients' greater ease of accessing the sense of security, does heighten the patients' self-efficacy and self-management ability. With no doubt, SDM is not suitable for all patients, e.g. some patients with anxiety traits extremely dislike SDM.

\section{Advantages of the TOP Meeting}

There is a shortage of quality psychiatric service in China. We need high-level teachers, practitioners and administrators of Psychiatry. This meeting fulfilled this demand by giving the Chinese psychiatrists a chance to communicate with the excellent international and Chinese experts. The content of this meeting covered most of the present focal issues. We have obtained universal positive feedback from the 
participants, most of whom expressed their willingness to join next year.

\section{Limitations of the TOP Meeting}

There were still some limitations of the TOP.

1. The schedule was very tight.10 lectures and 3 workshops were scheduled to take place within one day and a half. Participants had to rush and could not have enough rest that may impede their participating performance.

2. There were too many contents in the meeting. Some of the topics were not discussed deeply enough. Some of the topics seemed too simple to some of the participants. Maybe next year, we should do some investigation and prioritization before making the schedule.

3. About $2 / 3$ participants didn't complete the feedback tables because of the lack of time. Some of them thought the paper-based tables were bothering. Next year, we will use more convenient and more accessible computerized questionnaires. 


\section{University Library}

\section{- M M I E R R V A gateway to Melbourne's research publications}

Minerva Access is the Institutional Repository of The University of Melbourne

Author/s:

Li, Y;Sartorius, N;Herrman, H;Mian-Yoon, C;Li, T;Yi, H;Heok, KE

Title:

Teachers of Psychiatry Meeting in Chengdu

Date:

2017-12-01

Citation:

Li, Y., Sartorius, N., Herrman, H., Mian-Yoon, C., Li, T., Yi, H. \& Heok, K. E. (2017).

Teachers of Psychiatry Meeting in Chengdu. ASIA-PACIFIC PSYCHIATRY, 9 (4), https:// doi.org/10.1111/appy.12306.

Persistent Link:

http://hdl.handle.net/11343/293936 